\title{
Uma nova abordagem dos estudos da medicina tradicional chinesa no Ocidente
}

JACQUES, Lilian Moreira.

\section{As Bases Científicas da Medicina Tradicional Chinesa.}

1. ed. São Paulo: Annablume, 2005.

\section{| ${ }^{1}$ Sabrina Pereira Rocha, ${ }^{2}$ Dante Marcello Claramonte Gallian |}

${ }^{1}$ Mestranda do Programa de Pós- graduação em Saúde Coletiva, Departamento de Medicina Preventiva da Universidade Federal de São Paulo (UNIFESP), São Paulo, Brasil. Endereço eletrônico: sp.rocha1986@uol.com.br

${ }^{2}$ Docente e diretor do Centro de História e Filosofia das Ciências da Saúde (CeHFi-UNIFESP), São Paulo, Brasil; professor e pesquisador visitante do Centre de Recherches Historiques da École des Hautes Études en Sciences Sociales de Paris, França. Endereço eletrônico: dante.cehfi@epm.br

O livro As bases científicas da medicina tradicional chinesa é resultado da dissertação de mestrado de Lilian Moreira Jacques, defendida em 2003 no Programa de História das Ciências e das Técnicas e Epistemologia do Curso de Pós-graduação em Engenharia de Sistemas de Computação na Coppe/UFRJ.

Lilian Moreira Jacques é bacharel em Economia pela Universidade Federal do Rio de Janeiro e em Fisioterapia pela Universidade Estácio de Sá; mestre em História das Ciências e das Técnicas e Epistemologia pela Universidade Federal do Rio de Janeiro. Acumulou ampla experiência no quesito "medicina tradicional chinesa”, primeiramente por especializar-se em Tui $\mathrm{Na}$ pelo International Acupuncture Training Center de Pequim, China, em 1995, e posteriormente por dedicar-se ao ensino dessa prática. Possui vasto conhecimento em ciências cognitivas, área em que atualmente desenvolve pesquisa na Universidade do Arizona, Estados Unidos.

O livro é constituído de breve apresentação e introdução, e os temas são retratados em cinco capítulos. A apresentação é escrita por Luís Alfredo Vidal de Carvalho, orientador da autora na elaboração de sua dissertação de mestrado. Este possui graduação em Engenharia Mecânica, mestrado em Engenharia Mecânica e doutorado em Engenharia de Sistemas e Computação pela Universidade Federal do Rio de Janeiro, com ênfase em redes neuronais e modelos em neurofisiologia, e 
suas pesquisas sempre estiveram direcionadas às áreas interdisciplinares reunindo Neurociências, Psicanálise, Filosofia e Biologia.

Em sua sinóptica apresentação, Carvalho aponta a relevância do estudo realizado por Lilian Moreira Jacques, enfatizando a escassez de trabalhos no Brasil que, como esse, investiga a ação da acupuntura, bem como a importância de instituições como a Coppe/UFRJ, o Instituto de Medicina Social da Universidade do Estado do Rio de Janeiro (UERJ), a Fundação Oswaldo Cruz e a Universidade Federal de São Paulo (UNIFESP) dentro de um cenário em que as pesquisas no campo da medicina tradicional chinesa encontram sérias dificuldades de financiamento. Levanta a importante questão da disputa política e jurídica, mostrando uma evidente dicotomia, onde médicos e não médicos lutam em campos diferentes, e que esta polêmica, associada à morosidade da aceitação dessa modalidade terapêutica pela comunidade biomédica, acaba dificultando a expansão da acupuntura. Faz uma pequena reflexão sobre a relevância dos modelos computacionais nas pesquisas relacionadas a esse campo, embora haja ainda grande dificuldade para desenvolver estudos clínicos no campo da acupuntura e da biomedicina. Finaliza evidenciando a importância da abordagem histórica realizada pela autora diante desse impasse.

$\mathrm{Na}$ introdução, Jacques expõe sucintamente a organização do livro e demonstra seu interesse em estabelecer uma relação entre o modelo chinês tradicional e o modelo biomédico. Para a autora, o resgate histórico da medicina tradicional chinesa contribui para o entendimento da absorção deste sistema de atenção à saúde pelas sociedades ocidentais. Ela aborda a medicina tradicional chinesa como um sistema médico complexo, visão esta que se aproxima da categoria operacional "racionalidade médica", criada por Luz (TESSER; LUZ, 2008). A racionalidade médica pode ser entendida como:

[...] um conjunto integrado e estruturado de práticas e saberes composto de cinco dimensões interligadas: uma morfologia humana (anatomia, na biomedicina), uma dinâmica vital (fisiologia), um sistema de diagnose, um sistema terapêutico e uma doutrina médica (explicativa do que é a doença ou adoecimento, sua origem ou causa, sua evolução ou cura), todos embasados em uma sexta dimensão implícita ou explícita: uma cosmologia. (TESSER; LUZ, 2008, p. 196).

No primeiro capítulo, O campo da medicina tradicional chinesa, a autora, através de uma abordagem histórica, descreve a origem e os princípios fundamentais da acupuntura enquanto sistema médico, e para justificar sua 
articulação utiliza referenciais teóricos de autores como Joseph Needham, Marcel Granet e Paul Unschuld. Nesse capítulo, Jacques descreve a sociedade chinesa associando as características das diferentes dinastias ao desenvolvimento do campo da medicina tradicional chinesa. Apresenta a teoria do Yin e Yang, relacionando-a tanto às estruturas e funções orgânicas, quanto às manifestaçôes clínicas. Explica de maneira breve e sistemática a relevância da Doutrina das Cinco Fases, para elaborar um diagnóstico e identificar o padrão de desarmonia para, posteriormente, determinar o tratamento a ser adotado, a fim de restaurar o equilíbrio do organismo. Estuda também a origem do conceito $c h$ ’ $i$, frisando que seu significado vem sendo reinterpretado ao longo da história como "energia, energia vital, energia sutil, força vital, pneuma e, por último, como informação" (JACQUES, 2005, p.37). Afirma também que a "correspondência da ideia de $c h$ 'i com o conceito de energia da física” tem como objetivo adaptar esta concepção “ao discurso científico contemporâneo" (JACQUES, 2005, p.37). Finaliza o capítulo compilando elementos da história recente da medicina tradicional chinesa, destacando o encontro entre o paradigma chinês e o ocidental.

A Teoria dos Meridianos Jing-Luo é o segundo capítulo, no qual Lilian Moreira Jacques explica que os termos Jing e Luo foram traduzidos nas línguas ocidentais, respectivamente, como "meridiano, canal ou conduíte" e "vaso de ligação ou vaso colateral". A autora expõe que "o interesse científico contemporâneo pela teoria dos meridianos suscitou um debate a respeito da existência física dessas estruturas" (JACQUES, 2005, p.56). Segundo Jacques:

[...] o sistema de meridianos tal como se estuda hoje é constituído por um conjunto
de estruturas com funções específicas: doze meridianos principais, oito meridianos
extraordinários, doze meridianos distintos, quinze meridianos colaterais, doze meri-
dianos tendinomusculares e doze zonas cutâneas. Afirma ainda que a finalidade deste
complexo sistema é promover a relação entre as substâncias vitais (ch'i, xue, jing ye,
Jing e Shen) e os órgãos e vísceras (zang fu).

Considerando estas inter-relações, ela descreve brevemente as substâncias vitais. Explora um pouco mais o conceito de $c h$ ' $i$, descrito mais detalhadamente no primeiro capítulo, abordando os conceitos de ying-ch'i (ch'i nutritivo) e wei ch' $i$ (ch' $i$ defensivo). Perscruta os termos xue (sangue), forma mais densa de $c h^{\prime} i$, nutre e umedece os tecidos; jing ye (líquidos orgânicos) que auxiliam na formação do sangue e no umedecimento de tecidos, órgãos e vísceras; Jing (essência) que abrange aspectos hereditários (genoma) e adquiridos (alimentos), sendo responsável 
pelo desenvolvimento, desde a concepção até a morte; e Shen (espírito ou mente) cuja função de promover as atividades vitais do indivíduo pode ser observada na expressão facial e oral, no brilho dos olhos e nos processos de pensamento.

Ainda no segundo capítulo, é mostrada a existência de uma proximidade das ideias chinesas e ocidentais relacionadas ao mecanismo de funcionamento dos órgãos e vísceras, embora as ideias chinesas não estejam embasadas nos conceitos de física e química, característica da biomedicina moderna. É descrito ainda o acoplamento entre os zang, "órgãos maciços, de natureza Yin, responsáveis pela produção e armazenamento das substâncias vitais”, e $f u$, vísceras ocas, "responsáveis por receber e digerir os alimentos, absorver as substâncias e nutrientes e excretar os resíduos". Jacques oferece uma breve conceituação, padronização e classificação dos pontos de acupuntura, destacando ainda uma série de estudos realizados com o propósito de investigá-los à luz da ciência moderna. Apresenta uma conceituação da unidade de medida relativa (cun), para localizar os pontos de acupuntura e questiona a aplicabilidade dessa medida, devido a um estudo realizado em funcionários e alunos do College of Traditional Chinese Medicine, da University of Tecnology, em Sidney, Austrália, demonstrando discrepâncias significativas da referida medida.

A autora inicia o terceiro capítulo, O processo de validação clínica da teoria dos meridianos segundo os critérios da Medicina Ocidental, com uma indagação do diplomata e precursor da acupuntura no Ocidente, Soulié de Morant (1972, p. 20-21): “o que a acupuntura pode curar?”. Ele responde que a acupuntura é eficaz em alterações funcionais, mas quando se tornam lesōes orgânicas, é necessária uma intervenção medicamentosa ou cirúrgica. São relatados alguns trabalhos publicados em revistas francesas deste e de outros autores da época, meados do século $\mathrm{XX}$, que embora não atendam aos "critérios científicos exigidos nos estudos clínicos de hoje [...] ocupam um lugar simbólico no início da construção da ponte entre o campo da acupuntura e o da comunidade biomédica ocidental" (JACQUES, 2005, p.85).

A investigadora descreve diversos trabalhos que apresentam problemas metodológicos nos estudos clínicos da eficácia da acupuntura, e que mesmo com a melhoria da qualidade da metodologia empregada nesses estudos, a partir das décadas de 1980 e 1990, ainda assim "delinear experimentos que contemplem os critérios básicos dos campos básicos de acupuntura e da biomedicina permanece 
um desafio" (JACQUES, 2005, p.86). Afirma que é necessário desenvolver novas ferramentas metodológicas "para eliminar as fontes de possíveis distorções na análise dos resultados", visto que "as condições dos estudos clínicos controlados com randomização não podem ser cumpridas por completo nos estudos clínicos de acupuntura”. Apresenta as conclusōes e recomendaçôes do documento Consensus Statement on Acupuncture, gerado em 1997 pela conferência organizada pelo National Institutes of Health (NIH). Abarca brevemente os programas de ensino de acupuntura nos Estados Unidos e no Brasil, evidenciando a dificuldade do tratamento, devido à não familiaridade das teorias chinesas à luz da medicina ocidental, bem como a intercorrência de efeitos adversos e alguns aspectos legais e éticos exigidos pela prática de acupuntura.

O quarto capítulo, As bases neurofisiológicas da acupuntura chinesa, é marcado pela interlocução entre os achados ocidentais e o mecanismo de funcionamento da acupuntura. A pesquisa científica sobre os mecanismos de ação da acupuntura começou em 1965 no laboratório de Han Jisheng, em Pequim, com o objetivo inicial de comprovar se a acupuntura possuía efeito analgésico. Este capítulo é repleto de informações acerca da hipótese neuroendócrina da acupuntura. Para tanto, a pesquisadora utiliza diversos artigos científicos e livros consagrados de fisiologia e neurociência. Neste capítulo encontra-se a descrição dos estímulos somato-sensoriais com uma observação mais profunda da submodalidade dor, apresentando a teoria do "portão da dor", com ênfase nos estudos posteriores à primeira versão desta teoria, pois estes últimos proporcionaram uma explicação mais aceitável para alguns fatos clínicos. Ainda neste capítulo, é destacado que a formulação da teoria neuroendócrina favoreceu o entendimento do mecanismo de ação da acupuntura, no que tange aos efeitos analgésicos e anti-inflamatórios, porém não foi satisfatória para explicar a teoria dos meridianos, contemplando apenas o entendimento dos pontos de acupuntura.

$\mathrm{O}$ último capítulo, O nexo entre a teoria dos meridianos e pontos de acupuntura $e$ as ciências biomédicas, é de certa forma um prosseguimento do capítulo anterior, e abrange possíveis explicações da teoria dos meridianos. A primeira abordagem descreve artigos científicos sobre a relação entre a rede de meridianos e pontos de acupuntura e a transdução de sinais mecânicos nas células do tecido conjuntivo. A provável explicação para a irradiação do sinal mecânico para além da região de puntura é que a manipulação da agulha de acupuntura gera uma série de reações 
no tecido conjuntivo, e que a deformação causada no tecido não está limitada à área de inserção da agulha, pois se dissemina pelos diversos planos de tecido conjuntivo. A segunda abordagem estabelece a relação entre a rede de meridianos e os pontos de acupuntura e as propriedades eletromagnéticas funcionais dos organismos vivos. Para isso, a autora também lança mão de estudos científicos relacionados ao tema.

O reconhecimento das propriedades bioelétricas dos pontos de acupuntura [...] permitiu que se postulasse uma natureza eletromagnética para estas estruturas. O sistema de meridianos corresponderia a um sistema de transdução de sinais intercelulares anterior aos sistemas fisiológicos, inclusive o sistema nervoso. (JACQUES, 2005, p. 152).

Nas considerações finais, são retomadas as características dos modos de pensar dos diferentes segmentos, ciência biomédica contemporânea e medicina tradicional chinesa, enfatizando os consensos, divergências e ambiguidades. Ao final, a escritora expõe algumas perspectivas, tais como: a relevância do desenvolvimento das pesquisas de acupuntura com a utilização de tecnologia moderna para entender melhor seus mecanismos de ação, reforçando a ideia da importância da expansão das pesquisas relatadas nos capítulos 4 e 5; a importância da incorporação de preceitos gerais da medicina tradicional chinesa (doutrinas Yin/Yang e Cinco Fases, substâncias vitais, semiologia e princípios de diagnóstico) em estudos clínicos e laboratoriais.

Recomenda-se a leitura deste livro, no qual o(a) leitor(a) encontrará uma análise dos aspectos históricos, filosóficos e culturais do vasto campo da medicina tradicional chinesa. Este antigo conhecimento se baseia em conceitos e teorias que dificultam a aceitação e a assimilação desta prática no Ocidente. Jacques foi capaz de situar e privilegiar os mecanismos de ação da acupuntura, buscando os elementos que apresentam similaridade e compatibilidade entre os dois modelos. Nesta perspectiva, as pesquisas científicas contribuem para um maior entendimento da acupuntura, garantindo sua aceitação no contexto médico como uma prática válida. No entanto, as pesquisas científicas no campo da medicina tradicional chinesa, em particular da acupuntura, ainda são escassas no Brasil, e o trabalho de Lilian Moreira Jacques ocupa lugar de especial destaque nesse contexto. 
Por fim, é necessário destacar que o livro As bases cientificas da medicina tradicional chinesa caracteriza-se como importante instrumento de ampla aplicabilidade nos estudos tanto no âmbito da Saúde Coletiva quanto das pesquisas clínicas, visto que a autora traz uma reflexão sobre a pertinência da incorporação da dimensão epistemológica da acupuntura nos estudos científicos que versam sobre o tema, bem como a carência e as dificuldades encontradas pelo modelo biomédico nas pesquisas relacionadas à acupuntura, assumindo como pressuposto a necessidade de uma mudança no perfil das pesquisas sobre essa prática milenar. ${ }^{1}$

\section{Referências}

JACQUES, L.M. As bases cientificas da medicina tradicional chinesa. 1. ed. São Paulo: Annablume, 2005.

SOULIÉ DE MORANT, G. L'acuponcture chinoise. Paris: Maloine, 1972.

TESSER, C.D.; LUZ, M.T. Racionalidades médicas e integralidade. Ciênc. saúde coletiva. Rio de Janeiro, v.13, n.1, p. 195-206, 2008.

\section{Nota}

${ }^{1}$ Os autores participaram igualmente de todas as etapas de elaboração da resenha. 